\title{
Honeywell
}

\section{Conveyorized Photoresist Stripping Replacement for Flex Circuit Fabrication}

Federal Manufacturing \& Technologies

M. Donahue

KCP-613-8239

Published October 2007

Final Report

Approved for public release; distribution is unlimited.

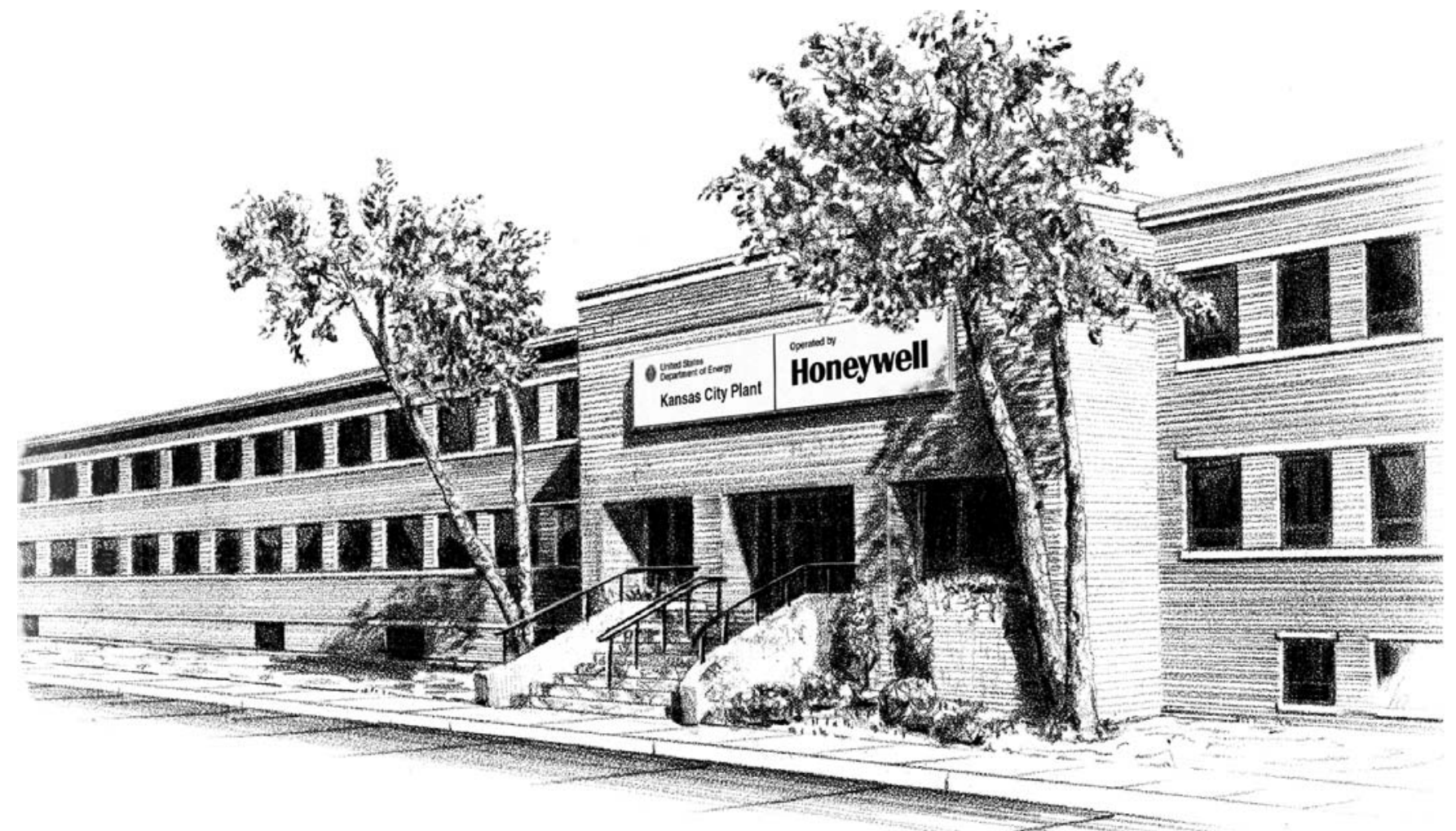

Prepared under prime contract DE-ACO4-01AL66850 for the

United States Department of Energy 


\section{DISCLAIMER}

This report was prepared as an account of work sponsored by an agency of the United States Government. Neither the United States Government nor any agency thereof, nor any of their employees, makes any warranty, express or implied, or assumes any legal liability or responsibility for the accuracy, completeness, or usefulness of any information, apparatus, product, or process disclosed, or represents that its use would not infringe privately owned rights. Reference herein to any specific commercial product, process or service by trade names, trademark, manufacturer, or otherwise, does not necessarily constitute or imply its endorsement, recommendation or favoring by the United States Government or any agency thereof. The views and opinions of authors expressed herein do not necessarily state or reflect those of the United States Government or any agency thereof.

All data prepared, analyzed and presented has been developed in a specific context of work and was prepared for internal evaluation and use pursuant to that work authorized under the reference contract. Reference herein to any specific commercial product, process or service by trade name, trademark, manufacturer, or otherwise, does not necessarily constitute or imply its endorsement, recommendation or favoring by the United States Government, any agency thereof or Honeywell Federal Manufacturing \& Technologies, LLC.

Printed in the United States of America.

This report has been reproduced from the best available copy.

Available to DOE and DOE contractors from the Office of Scientific and Technical Information, P.O. Box 62, Oak Ridge, Tennessee 37831; prices available from (865) 576-8401, FTS 626-8401.

Available to the public from the National Technical Information Service, U.S. Department of Commerce, 5285 Port Royal, Rd., Springfield, Virginia 22161, (703) 487-4650.

A prime contractor with the United States Department of Energy under Contract Number DE-AC04-O1AL66850
Honeywell Federal Manufacturing \& Technologies

P.O. Box 419159

Kansas City, Missouri, 64141-6159 


\title{
Honeywell
}

KCP-613-8239

Distribution Category UC-42

Approved for public release; distribution is unlimited.

\section{CONVEYORIZED PHOTORESIST STRIPPING REPLACEMENT} FOR FLEX CIRCUIT FABRICATION

\author{
M. Donahue \\ Department EE1 \\ Final Report \\ Project Team: \\ D. Laughlin \\ D. Hanson \\ M. Beaty \\ T. Burke \\ M. McHenry
}

Published October 2007 



\section{Contents}

Section Page

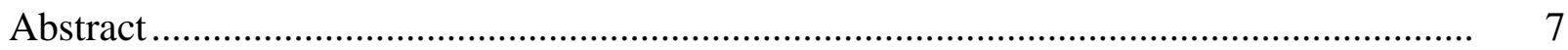

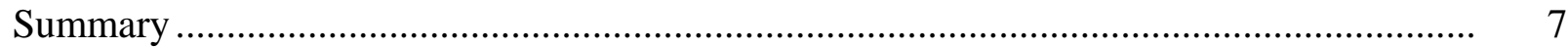

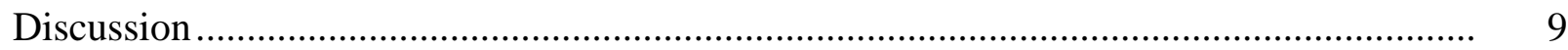

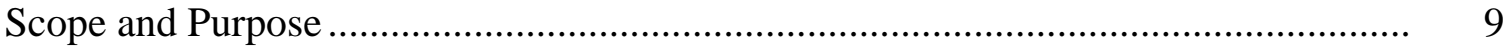

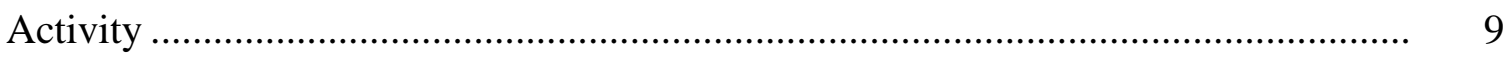

Photoresist Stripping Process...................................................................... 9

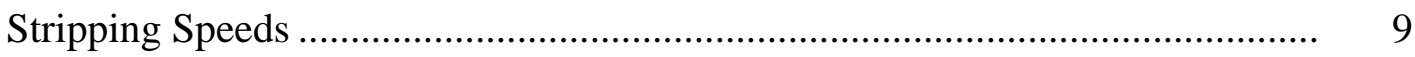

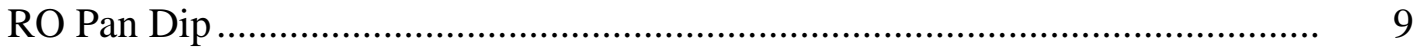

Peel Strength Samples ..................................................................... 10

Rollers and Leader Boards ..................................................................... 10

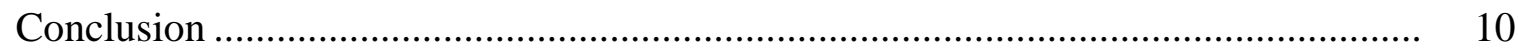

Appendix

Statistical Analysis................................................................................... 11 
This Page Intentionally Left Blank 


\begin{abstract}
A replacement conveyorized photoresist stripping system was characterized to replace the ASI photoresist stripping system. This system uses the qualified ADF-25c chemistry for the fabrication of flex circuits, while the ASI uses the qualified potassium hydroxide chemistry. The stripping process removes photoresist, which is used to protect the copper traces being formed during the etch process.
\end{abstract}

\title{
Summary
}

ASI went out of business some years ago and rising maintenance costs began to rival the cost of a new stripping system. A decision was made to replace the ASI stripping system. The Chemcut stripping system duplicates the functions of the ASI system but includes enhanced control, rinsing, and conveyor systems.

Qualification activities included comparing peel strengths of laminated test panels, photoresist stripping speeds, and the removal of resist between the two stripping systems.

This study demonstrates that the Chemcut photoresist stripper meets or exceeds production requirements for flex circuit fabrication. 
This Page Intentionally Left Blank 


\section{Discussion}

\section{Scope and Purpose}

This evaluation was done to qualify a replacement stripping system used to remove photoresist from the copper surfaces of flex circuits.

\section{Activity}

\section{Photoresist Stripping Process}

Both the ASI machine and the Chemcut machine have a stripping chamber followed by rinses and a dryer. The two machines differ in two ways. The chemical used in the ASI process is potassium hydroxide while that in the Chemcut process is ADF-25c. ADF-25c was approved for use in EER 20031565SA Revision 2. The second difference is the rinsing process. Currently, the ASI process uses a two chamber cascade rinse and a high pressure rinse chamber while the Chemcut process uses a three-chamber cascade rinse.

\section{$\underline{\text { Stripping Speeds }}$}

The ASI conveyor speed for a copper panel with DuPont Multimaster115mmi photoresist is typically set at 2.5 to 3.0 feet per minute. The Chemcut conveyor speed for the same panel type was typically set at 2.0 to 2.5 feet per minute.

The ASI conveyor speed is typically set at 4.0 to 4.5 feet per minute for an aluminum panel with DuPont Multimaster115mmi photoresist. The Chemcut conveyor speed for aluminum panels is the same as the conveyor speed for the copper panel (2.0 to 2.5 feet per minute).

The advantage of same copper and aluminum conveyor set points is a less likely chance for errors to occur when setting the conveyor speeds. Another advantage to the Chemcut machine is that the viewing glass has not been etched by the chemical usage. This allows the user to verify where the photoresist is being removed from the panels in the stripping chamber, also known as the breakpoint.

\section{RO Pan Dip}

Stripped panels were dipped into hot RO water to expose any unremoved photoresist. Any photoresist not removed by the stripping system would turn a bright blue. Ten panels were run through each stripping machine and then dipped into a pan of hot RO water. After being dipped into the pan of water, the Chemcut panels only showed two particles of unremoved photoresist under the size of 1 millimeter square. The ASI panels also had two particles under the size of 1 millimeter. However, the ASI panels also yielded four photoresist particles of about 5 millimeters. 


\section{Peel Strength Samples}

Peel Strength tests were performed to compare the amount of force necessary to delaminate a cable after lamination. From each stripping machine, 10 sets of two panels were laminated together for both $1 \mathrm{oz}$ copper and 1 mil aluminum. Three peel strength samples were then taken from each set of panels.

Statistical analysis of the peel test data was performed to determine the significance of the data. Both the ASI and Chemcut stripping process exhibited Cp and Cpk values greater than 1.0 for both aluminum and copper. A Cp/Cpk value that is greater than one indicates that the process is in control.

The greater the $\mathrm{Cp}$, the tighter the distribution. For both copper and Aluminum, the ASI had a higher Cp, or a tighter distribution. While the ASI machine’s Cp may be higher, three sigma from the mean leaves the Chemcut machine with higher peel strengths for both the copper and aluminum. For the Chemcut machine, the copper and aluminum three sigma from the mean gives peel strengths of $3.175 \mathrm{lb} /$ in and $2.693 \mathrm{lb} / \mathrm{in}$, respectively. The ASI copper and aluminum values were only $3.101 \mathrm{lb} / \mathrm{in}$ and $1.534 \mathrm{lb} / \mathrm{in}$, respectively.

The data and the statistical analysis can be found in Appendix A.

\section{$\underline{\text { Rollers and Leader Boards }}$}

The material used for the panels that were processed through both of the stripping systems was double sided $1 \mathrm{oz}$ copper with 1 mil kapton and double sided 1 mil aluminum with 1 mil kapton. When processed on the ASI stripping system, both the copper and aluminum panels had to be run with leader boards to allow the panels to progress through the system without becoming entangled or marred by roller marks. In contrast, the Chemcut stripping system transported the parts easily with no leader boards and slight to no roller marks.

\section{Conclusion}

After reviewing the results of this study, the Chemcut photoresist stripping system is equivalent to or better than the ASI photoresist stripping system. Further characterization is currently under way to optimize the settings for Dupont Multimaster115 mmi photoresist on copper and aluminum, and also Dupont Multimaster120 mmi photoresist and the double application of photoresist. 


\section{Appendix}

\section{Statistical Analysis}

Table A1, below, contains peel strength values for both copper and aluminum panels that were processed using the Chemcut and ASI stripping machines used in the statistical analysis.

\begin{tabular}{|c|c|c|c|c|}
\hline & $\begin{array}{c}\text { ChemCut - } \\
\text { Al }\end{array}$ & ASI - Al & $\begin{array}{c}\text { ChemCut - } \\
\mathrm{Cu}\end{array}$ & $\mathrm{ASI}-\mathrm{Cu}$ \\
\hline 1 & 6.32 & 2.46 & 7.08 & 4.68 \\
\hline 2 & 7.08 & 2.65 & 3.66 & \\
\hline 3 & 5.18 & 2.71 & 6.60 & 4.80 \\
\hline 4 & 5.42 & 2.69 & 6.41 & 6.01 \\
\hline 5 & 6.23 & 3.32 & 10.34 & \\
\hline 6 & 3.87 & 4.01 & 6.14 & 6.39 \\
\hline 7 & 4.44 & 2.73 & 7.38 & \\
\hline 8 & 5.21 & 2.59 & 5.91 & 6.46 \\
\hline 9 & 5.74 & 2.79 & & \\
\hline 10 & 6.50 & 2.39 & 6.87 & 6.95 \\
\hline 11 & 6.38 & 3.07 & 7.29 & 5.42 \\
\hline 12 & 6.81 & 2.51 & 9.11 & 5.09 \\
\hline 13 & 6.51 & 2.93 & 7.27 & 6.52 \\
\hline 14 & 5.88 & 2.82 & 6.97 & 6.90 \\
\hline 15 & 5.17 & 2.40 & 7.17 & 4.58 \\
\hline 16 & 5.00 & 2.43 & 8.57 & 4.90 \\
\hline 17 & 3.80 & 1.86 & 7.84 & 7.86 \\
\hline 18 & 4.61 & 2.39 & 7.18 & 5.98 \\
\hline 19 & 5.17 & 2.56 & 8.38 & 6.83 \\
\hline 20 & 5.26 & 2.48 & 6.80 & 5.28 \\
\hline 21 & 5.16 & 2.77 & 6.37 & 6.41 \\
\hline 22 & 4.91 & 3.16 & 7.24 & 7.07 \\
\hline 23 & 5.44 & 2.73 & 8.01 & 5.68 \\
\hline 24 & 4.84 & 2.24 & 6.52 & 5.59 \\
\hline 25 & 3.92 & 2.90 & 9.00 & 6.18 \\
\hline 26 & 4.45 & 2.89 & 7.38 & 5.41 \\
\hline 27 & 4.80 & 2.46 & 7.02 & 5.64 \\
\hline 28 & 4.75 & 2.95 & 8.00 & 6.93 \\
\hline 29 & 5.54 & 2.81 & 7.32 & 5.49 \\
\hline 30 & 4.72 & 2.36 & 11.29 & 8.47 \\
\hline Sample Count: & 30 & 30 & 30 & 30 \\
\hline $\begin{array}{l}\text { Average: } \\
\text { Standard }\end{array}$ & 5.30 & 2.70 & 7.42 & 6.06 \\
\hline Deviation: & 0.862 & 0.386 & 1.402 & 0.976 \\
\hline
\end{tabular}

Note: The missing data points are from peel strength samples that failed to produce data. 
A capability study was performed in MiniTab with the above data. It provided the following graphs, along with the mean, standard deviation, Cp, and Cpk values included in the margins of the graphs.

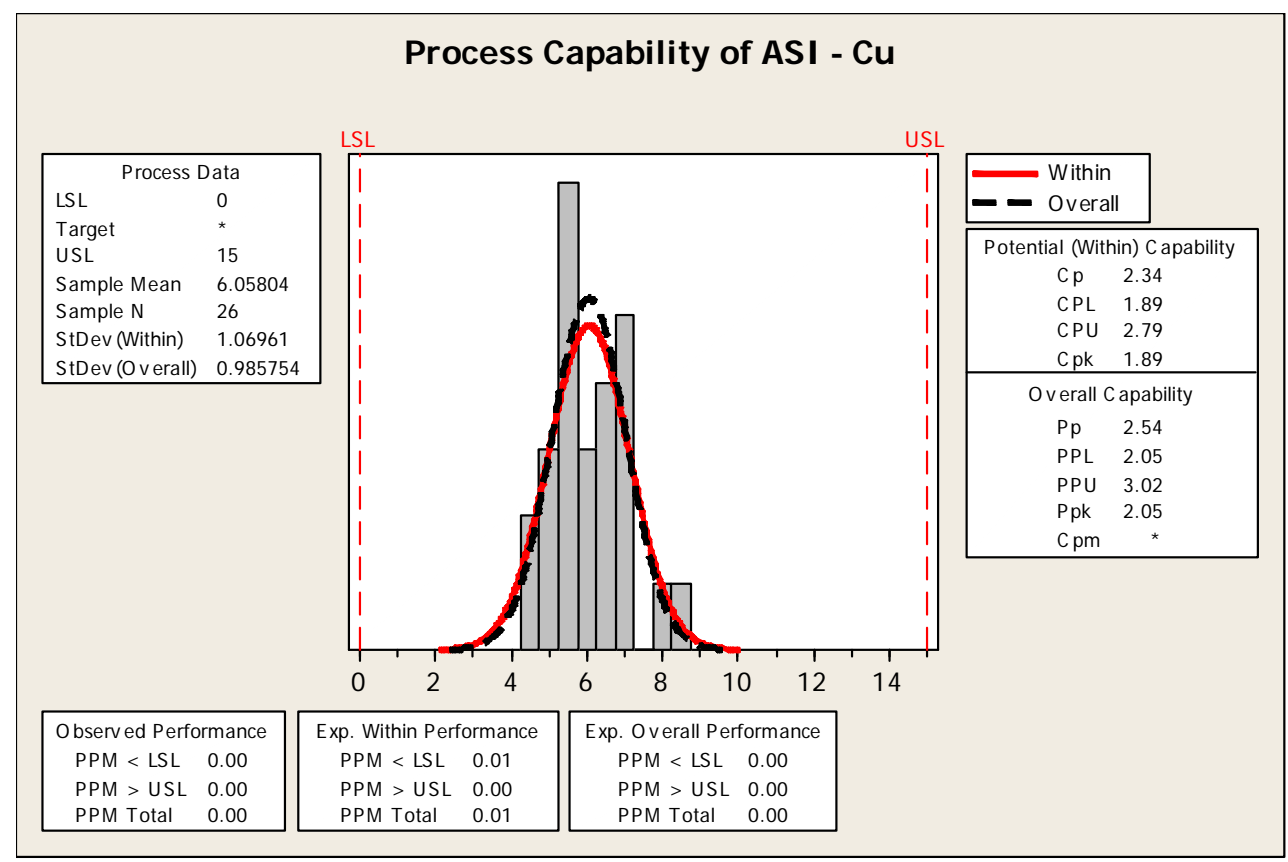

Graph A1 - Copper run through the ASI

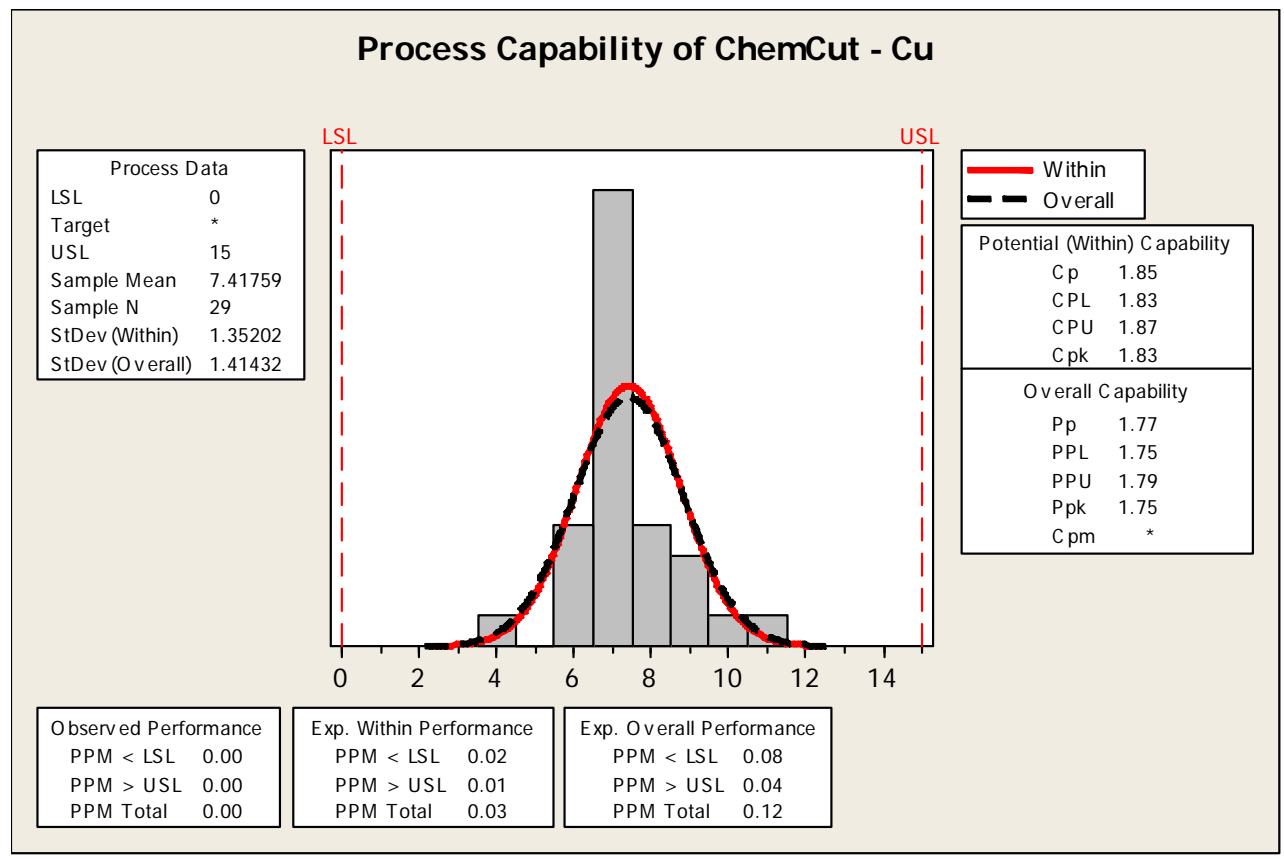

Graph A2 - Copper run through the Chemcut 


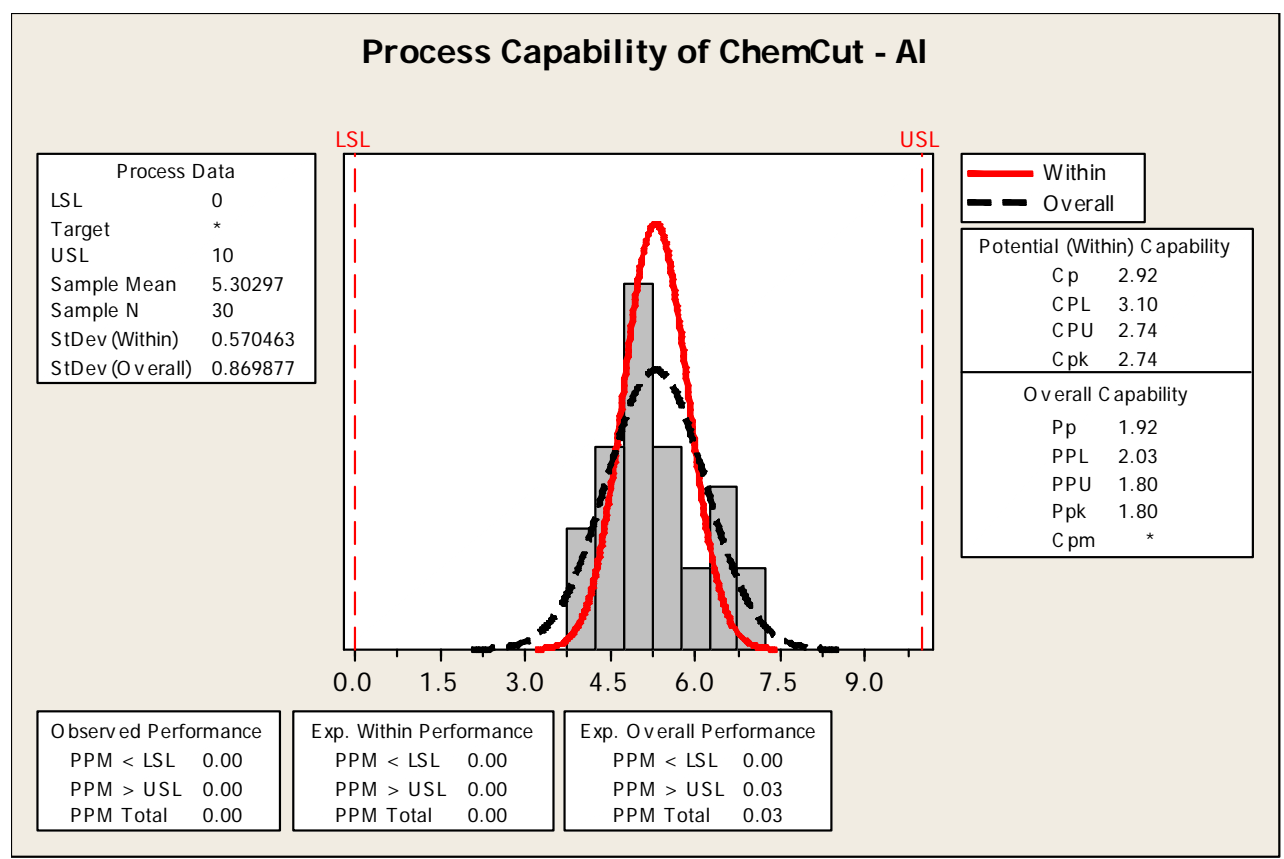

Graph A3 - Aluminum run through the Chemcut

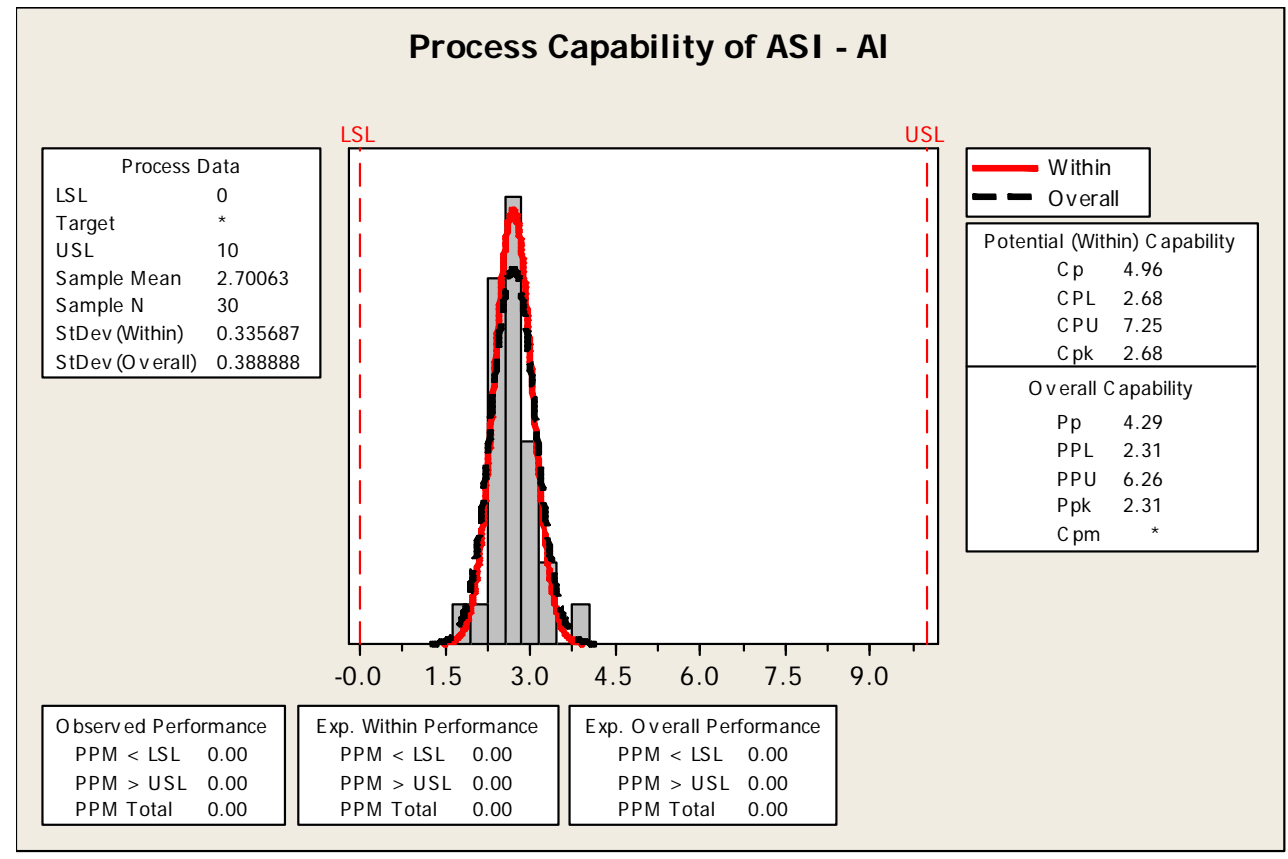

Graph A4 - Aluminum run through the ASI 